\title{
Obstetrical Haemorrhagic Mortality in a Tertiary Hospital of the
}

\section{Limpopo Province, South Africa}

\author{
Sam T Ntuli ${ }^{{ }^{*}}$ \\ ${ }^{1}$ Department of Public Health, University of Limpopo.Sovenga, South Africa \\ *Sam T Ntuli, E-mail: tsntuli@hotmail.com
}

Received: March 28, 2017

doi:10.22158/mshp.v1n1p42
Accepted: April 9, 2017

Online Published: April 18, 2017

URL: http://dx.doi.org/10.22158/mshp.v1n1p42

\begin{abstract}
Background: Obstetric haemorrhage is potentially fatal. Its frequency contributes to assessment of population health. So this study purpose was to assess the maternal deathsdue to obstetric haemorrhage in a tertiary hospital of the Limpopo Province, South Africa.

Methods: Allmaternal deaths, which occurred at Pietersburg Hospitalfrom January 2011 to December 2015 were reviewed. The hospital death register was used to collate the list of maternal deaths.Maternalage, parity, referring facility, date of admission and death, ward where death occurred, and causes of deathwere collected from delivery registers and patient medical records.
\end{abstract}

Results: There were 232 maternal deaths of which 48 (20.7\%) were due to obstetrical haemorrhage. The mean age of the 48 women was 31.7 46.7 year range 15-48 years. Thirty one of 48 haemorrhagic deaths (65\%) occurred within 24 hours of admission, 16 of 48 (33\%) had a parity of 3 or more, 19 (40\%) died in ICU and 12 (25\%) in casualty. Forty three of 48 women (90\%) were referred, of which 36 (84\%) were from district hospitals. Post-partum haemorrhage accounted for 39 of 48 (81\%) deaths followed by unspecifiedante-partum haemorrhage accounting for 4 (8\%) and placenta abruption 2 of $48(4 \%)$.

Conclusion: This study demonstrated that a maternal death due to obstetric haemorrhage remains a major concern in Limpopo Province. Post-partum haemorrhage was the main cause of deaths.

\section{Keywords}

maternal, obstetric haemorrhage, tertiary hospital, South Africa

\section{Introduction}

Obstetric haemorrhage remains a major cause of maternal morbidity and mortality world wide with the highest incidence in developing countries. Many studies in developing countries have shown that haemorrhage attributed $15-30 \%$ of maternal deaths in tertiary hospitals. According to the National Committee of Confidential Enquiries into Maternal Deaths (NCCEMD) in South Africa (SA), 
haemorrhage accounted for a national average (15.8\%) of maternal deaths and most of these deaths occurred during or after a caesarean section. In spite of the increased awareness, training and protocols bleeding during or after delivery continues to be a major public health concern in rural provinces of SA particularly Limpopo Province (LP).

Buchman and co-authors in their study at Chris HaniBaragwanath Hospital in Gauteng province found that in 2015 obstetric haemorrhage caused 13\% of maternal deaths. In the same period, it was reported that $18 \%$ of obstetric Intensive Care Unit (ICU) admissions at tertiary hospital in LP were due to haemorrhage and $36 \%$ of those died. Lack of senior or experienced doctors available to help junior and inexperienced doctors and resuscitation equipment, blood bank and/or ICU have been reported to be behind haemorrhage-related deaths. Although the NCCEMD noted a reduction in maternal deaths between 2008/2010 and 2011/2013, haemorrhage related deaths increased particularly in LP.

Overwhelming number of obstetric haemorrhagic deaths occurred in the Capricorn district where the tertiary hospital is situated. It has not been documented why haemorrhage causemany maternal deaths in a tertiary hospital of the LP, and thus makes it necessary to investigate in detail these deaths to have a clear understanding of the situation and subsequently build capacity and support for the prevention and treatment of this condition. The purpose of this study was to determine maternal deaths associated with obstetric haemorrhage in tertiary hospital of the Limpopo province, South Africa. In addition, to assess the most common referring facilities.

\section{Materials and Methods}

A retrospective descriptive study in which a review of all maternal deaths which occurred at Pietersburg Hospital of the Limpopo Province, South Africa, was undertaken over a 5-year period (January 2011 to December 2015). The hospital is the only provincial tertiary hospital in Limpopo and it is situated in Polo wane - the provincial capital. It is the main referral hospital for maternal cases from all provincial public hospitals and, occasionally, from private hospitals in the Province. The institution has a 12-bed multidisciplinary Intensive Care Unit (ICU), which admits about 350-450 patients on average per annum, while the maternity ward has 50 beds with an average of 300 deliveries per month (Hospital Statistics). Ethics approval to conduct the study was obtained from the Sefako Makgatho Health Sciences University Research Ethics Committee (SMUREC Ethics Ref \#: SMUREC/H/222/22015: IR).

The hospital death register was used to identify and collate a list of maternal deaths that occurred during the study period. Medical records of maternal deaths were reviewed by the medical officer. Information on all the cases was extracted from the patient's case notes, labour unit registers and maternal mortality records. The total deliveries and live births for each year were obtained from the delivery registers. The anonymity and confidentiality of patient personal information were protected by unique patient identifier. The data collected included maternal age, gestation age, referring facility, date of admission, date of death, ward where death occurred, and cause of death. Data was captured and 
analysed using Microsoft ${ }^{\circledR}$ Excel (Microsoft Corporation) version 14 and STATA ${ }^{\circledR} 9.0$ (Stata Corp; College Station, TX), respectively. Descriptive statistics was used to analyse data. Categorical variables are displayed as percentages and continuous variables are reported as mean \pm Standard Deviation (SD).

\section{Results}

Two hundred thirty twomaternal deaths were recorded during the study period. The meanage of the women was 31.7+-6.7 year range 15-48 years. Forty eight of 232 maternal deaths (21\%) were due to obstetric haemorrhage. Most (68\%) of these deaths occurred in the young women (under 35 years old). Sixteen of 48 deaths (33\%) occurred in those with a parity of 3 or more and $19(40 \%)$ occurred in ICU and $12(25 \%)$ incasualty. Thirty one of 48 deaths $(65 \%)$ occurred within 24 hours of admission.

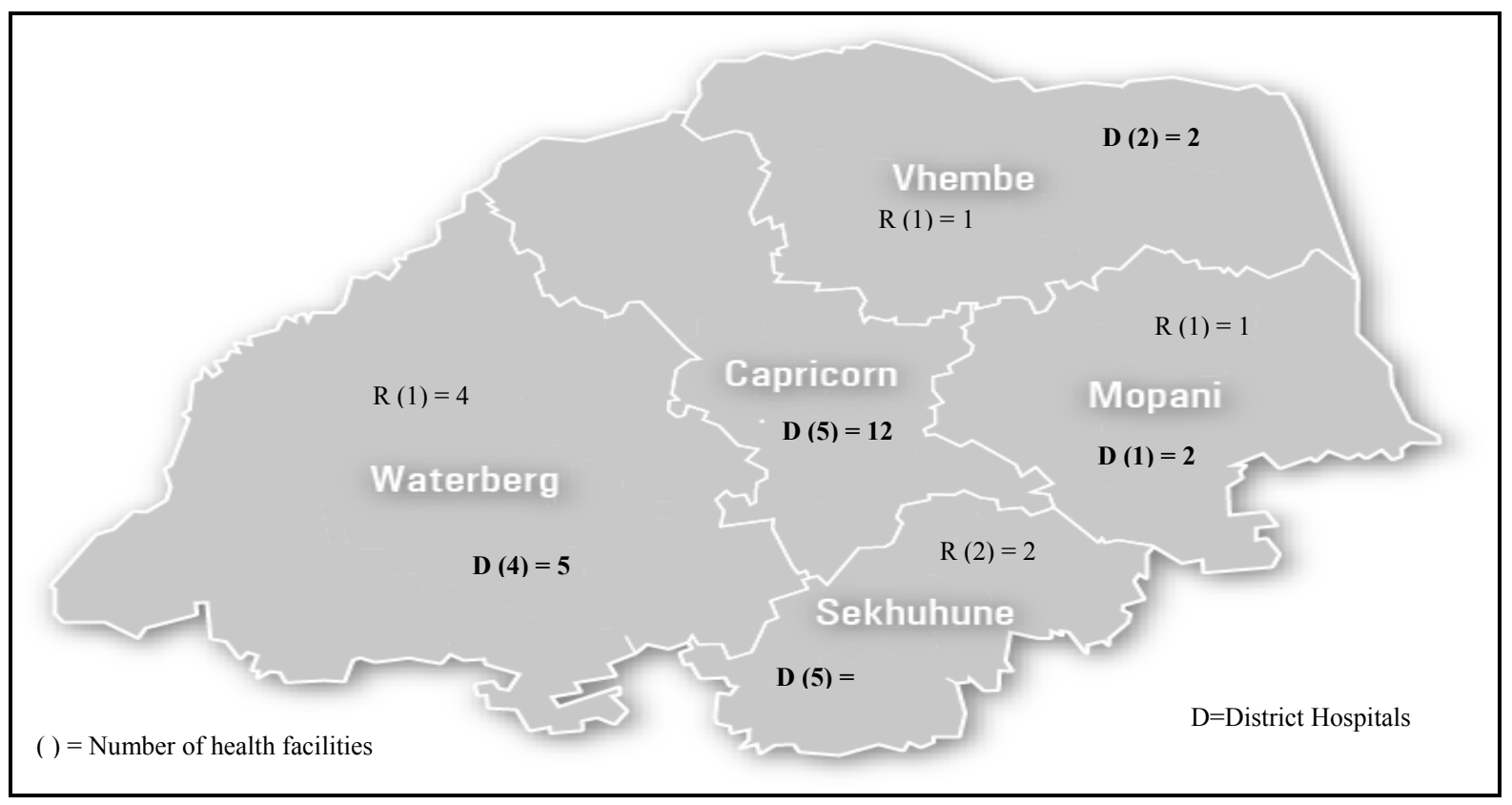

Figure 1. Level of Care at Which Women Were Referred $(n=43)$

The most common cause of obstetric haemorrhagic deaths were 39 (81\%) Postpartum Haemorrhage (PPH), 7 (15\%) unspecified Ante Partum Haemorrhage (APH) and 2 (4\%) placenta abruption. Forty three of 48 women who died of haemorrhage (90\%) were referred. Of the referred women $35(81 \%)$ were referred from district hospitals (Figure 1). Sixteen (37\%) were referred from Sekhukhune, of which 88\% (14/16) were from district hospitals. One district hospital in Sekhukhune referred 5/14. Capricorn with 12 of 43 referrals (28\%) was the second district to send many patients with one district hospital referred 4/12. Patients referred from any hospital outside Capricorn were deemed to have travelled for long. 


\section{Discussion}

The proportion of obstetric haemorrhage in the causes of maternal deaths in this study is worse than $13 \%$ reported from an urban teaching hospital in Gauteng province, South Africa. It is also higher than the national average of $15.8 \%$. The present resultis similar to some previous African studies that reported Haemorrhagic maternal mortality rates between $20-24 \%$. The reasons for high obstetric haemorrhagic deaths in this study is unclear but most deaths were referrals who travelled long distances, some died in casualty and others within 24 hours of admission suggesting the women were seriously ill even before arrival at this hospital and needed prompt appropriate intervention. The finding of this study has shown that the rate of haemorrhagic deaths in Limpopo may be high because of delayed intervention. It agrees with a report from Tanzania, however, the patient was the main contributor in Tanzania.

In this study, more than two-thirds of women were referred from District hospitals. District hospitals referred directly to tertiary rather than regional centres nearby; and some regional hospitals sent most of their patients to tertiary; this suggests lack of specialist service or ICU at regional hospitals which caused the delay in intervention. It is most likely that other District hospitals bypassed respective regional hospitals because those higher centres failed to function as such, and only tertiary could offer the needed service.The fact that district hospitals in Capricorn referred directly to tertiary shows that these hospitals need a functioning higher centre to refer patients.

The standard management of life threatening PPH requires high skill and adequate equipment as well as promptness by both the patient and healthcare provider. This report is the first to provide some evidence that there is deterioration in service delivery in Limpopo regional hospitals. This may be the underlying reason for poor outcome following obstetric haemorrhage deaths in the province. Nevertheless, poor service delivery would need to be verified since the present study was based at tertiary hospital.

The high frequency of younger women suffering obstetric haemorrhagic death differs from a previous Ghanaian study, which found increased number of maternal deaths in women aged 35 years and older. This difference may be because the South African women from Limpopo started bearing children at a young age. Commencing reproduction at an early age may lead to occurrence of young grand multiparas, which we found to be frequent. Early age reproduction or grand multiparity are risk factors for PPH. Our result agrees with the Tanzanian study that reported that the frequency of maternal deaths was highest in the young age group.

Although we have not evaluated the impact of educational programs such as Essential Steps in Managing Obstetric Emergencies (ESMOE) and Emergency Obstetric Simulation Training (EOST), it would be interesting to direct future research in this regard. Moreover, analyzing only maternal deaths may be misleading - conducting maternal near miss audits as a compliment to maternal death reviews could give more comprehensive analysis of risk factors and assist to improve professional practice. 


\section{Study Limitations}

As with retrospective studies, any missing data from patient files affect the reliability of the data, but this was minimised by reviewing admission and death registers and all files from the records department.

\section{Conclusion}

Haemorrhagic deaths increased with time in this study and post-partum haemorrhage was the most common diagnosis observed. Delayed intervention increased the risk of maternal death from haemorrhage. Delayed intervention was due to deterioration in service delivery.

\section{Acknowledgements}

I thank the staff of the Maternity and Records Divisions of the Pietersburg Hospital, especially Mohlake K. L.

And Esterhuyse T. for their assistance during this study. Thanks to Dr Petero Anguria, Dr Belete Woldu and Mrs ME Moshabelafor providing useful comments and suggestions.

\section{References}

Buchmann, E. J., Mnyani, C. N., Frank, K. A., Chersich, M. F., \& McIntyre, J. A. (2015). Declining maternal mortality in the face of persistently high HIV prevalence in a middle income Country. $\mathrm{Br}$ J ObstGynaecol, 122(2), 220-227. https://doi.org/10.1111/1471-0528.13064

Chibber, R., Al-Hijji, J., Al-Adwani, A. R., Rammah, A., Fouda, M., Al-Saleh, E., \& Tasneem, M. A. (2012). Trends in maternal mortality over 29 years in a Kuwait Tertiary Teaching Hospital: Signs of progress? $J$ MaternFetal Neonatal Med, 25(9), 1557-1563. https://doi.org/10.3109/14767058.2011.640373

Der E, M., Moyer, C., Gyasi, R. K., Akosa, A. B., Tetty, Y., Akakpo, P. K., Blankson, A., \& Anim, J. T. (2013). Pregnancy related causes of deaths in Ghana: A 5 Year retrospective study. Ghana Med $J$, 47(4), 158-163.

Ezegwi, H., Onoh, R., Ikeako, L., Onyebuchi, A., Umeora, O., Ezeonu, P., \& Ibekwe, P. (2013). Investigating maternal mortality in a public teaching hospital, Abakaliki, Ebonyi State, Nigeria. Ann Med Health Sci Res, 3(1), 75-80. https://doi.org/10.4103/2141-9248.109511

Fawcus, S., \& Moodley, J. (2011). Management of postpartum haemorrhage. SAJOG, 17(2), 26-27.

Gebhardt, G. S., Fawcus, S., Moodley, J., \& Farina, Z. (2015). National Committee for Confidential Enquiries into Maternal Deaths in South Africa. Maternal death and caesarean section in South Africa: Result from the 2012-2013 saving mothers Report of the National Committee for Confidential Enquiries into Maternal Deaths. $S$ Afr Med, 105(4), 287-291. https://doi.org/10.7196/SAMJ.9351

Murthy, B. K., Murthy, M. B., \& Prabhu, P. M. (2013). Maternal Mortality in a Tertiary Care Hospital: 
A 10-year Review. Int J Prev Med, 4(1), 105-109.

Nakimuli, A. et al. (2016). Maternal near misses from two referral hospitals in Uganda: A prospective cohort on incidence, determinants and prognostic factors. BMC Pregnancy Childbirth, 16(24). https://doi.org/10.1186/s12884-016-0811-5

National Department of Health. (2015). South Africa Saving Mothers 2011-2013: Sixth report on confidential enquiries into maternal deaths in South Africa. Pretoria: National Department of Health. Retrieved from http://www.doh.gov.za

Nelissen, E. J., Mduma, E., Erdal, H. L., Evjen-Olsen, B., van Roosmalen, J. J., \& Stekelenburg, J. (2013). Maternal near miss and mortality in a rural referral hospital in Northern Tanzania: A cross-sectional study. BMC Pregnancy Childbirth, 13(141). http://dx.doi.org/10.1186/1571-2393-13-141

Nelissen, E., Mduma, E., Broerse, J., Ersdal, H., Evjen-Olsen, B., van Roosmalen, J., \& Stekelenburg, J. (2013). Applicability of the WHO maternal near miss criteria in a low-resourse setting. PLOS One, 8(4). http://dx.doi.org/10.1372/journal.pone.0061248

Ntuli, T. S., Ogunbanjo, G., Nesengani, S., Maboya, E., \& Gibango, M. (2015). Obstetric intensive care admissions at a tertiary hospital in Limpopo Province, South Africa. Southern African J of Crit Care, 31(1), 8-10. https://doi.org/10.7196/SAJCC.164

Obiechina, A. J., Okechukwu, Z., Oguejiofor, C., Udegbunam, O., Nwajiaku, L., Ogbuokiri, C., \& Egeonu, R. (2013). Maternal mortality at NnamdiAzikiwe University Teaching Hospital, Southeast Nigeria: A 10-year review (2003-2012). Int $J$ Womens Health, 5, 431-436. http://dx.doi.org/10.2147/IJWH.S46988

Pembe, A. B., Paulo, C., D’mello, B. S., \& van Roosmalen, J. (2014). Maternal mortality at Muhimbili National Hospital in Dar-es-salaam, Tanzania in the year 2011. BMC Pregnancy Childbirth, 14, 320. http://dx.doi.org/10.1186/1471-2393-14-320

Say, L. et al. (2014). Global causes of maternal death: A WHO systematic analysis. Lancet Glob Health, 2(6). http://dx.doi.org/10.1016/S2214-109X (14)70227-X

Schoon, M. G. (2013). Impact of inter-facility transport on mortality in the Free State Province. $S$ Afr Med J, 103, 534-538. https://doi.org/10.7196/SAMJ.6828

Wandabwa, J. N., Businge, C., Lango-Mbenza, B., Mdaka, M. L., \& Kiondo, P. (2012). Peripartum hysterectomy: Two years experience at Nelson Mandela Academic Hospital, Mthatha, Eastern Cape South Africa. Afr Health Sci, 13(2), 469-474. 